\title{
PROJETO FIFA “OS 11 PELA SAÚDE”: UMA ANÁLISE QUALITATIVA
}

\author{
Simone Rechia \\ Universidade Federal do Paraná, Paraná, Curitiba, Brasil \\ Pedro Augusto Schaeffer \\ Universidade Federal do Paraná, Paraná, Curitiba, Brasil \\ Emília Amélia Pinto Costa Silva \\ Universidade Federal do Paraná, Paraná, Curitiba, Brasil \\ Luize Moro \\ Universidade Federal do Paraná, Paraná, Curitiba, Brasil
}

\begin{abstract}
Resumo
O projeto "Os 11 pela Saúde" trata-se de uma iniciativa da FIFA, desenvolvido nas aulas de Educação Física em algumas das cidades-sede da Copa do Mundo. No entanto questiona-se: Os objetivos e métodos do projeto "Os 11 pela Saúde" atendem as reais necessidades da comunidade local? Desta forma, este artigo apresenta um estudo documental que teve o objetivo de analisar o projeto da FIFA "Os 11 pela Saúde" para identificar como são abordadas as áreas da Saúde, Educação, Esporte e Lazer. Utilizou-se a análise de conteúdo temática. Percebeu-se que o projeto tem uma perspectiva higienista e algumas das suas perspectivas não condiz com a realidade brasileira. Observou-se que é necessário um diálogo mais próximo entre os organizadores do projeto, professores de Educação Física, escola e a comunidade em geral, para que valores como Saúde, Educação, Esporte e Lazer sejam concretizados a partir das fragilidades e interesses da população.
\end{abstract}

Palavras-chave: Copa do Mundo. Educação Física. Lazer. Esporte.

\section{Introdução}

O Brasil se encontra conhecido atualmente no cenário mundial como o país-sede de grandes eventos esportivos (SÁNCHEZ; BIENENSTEIN; MASCARENHAS, 2011). Receber o Pan-Americano em 2007, a Copa do Mundo de Futebol no ano de 2014 e, em 2016, as Olimpíadas, deixa claro o momento histórico de o país sediar grandes eventos em um curto espaço de tempo.

Sabe-se que os Megaeventos Esportivos podem representar oportunidades econômicas e sociais, visto que quando bem sucedidos possibilitam projeção e valorização da imagem das cidades-sede por meio das mídias nacionais e internacionais, podendo ainda ajudar no processo de reestruturação das cidades, no que tange à habitação, ao transporte, à segurança, à educação, entre outros (MATIAS, 2007). Sendo assim, tais eventos são impulsionadores do desenvolvimento socioeconômico mundial, pois geram impactos e legados positivos e negativos para as cidades-sede (RUBIO, 2007). 
Na tentativa de minimizar os impactos negativos e potencializar os positivos, acreditase ser de suma importância a participação popular na criação das ações e projetos que, previstos pela FIFA e pelos países-sede, são desenvolvidos em função de um Megaevento Esportivo. Por meio da participação popular, as necessidades locais poderiam ser identificadas e, consequentemente, políticas seriam criadas para suprir tais necessidades, a partir do diálogo entre a comunidade e o poder público.

No caso da Copa do Mundo, uma das estratégias criada pela FIFA é a implantação do Projeto "Os 11 pela Saúde". Por meio do futebol, esse projeto, recentemente aplicado na África do Sul, tem o intuito de proporcionar melhorias nas questões relacionadas à Saúde, à Educação e ao Esporte. O projeto conta com a participação de jogadores de renome mundial e tem várias seções que fornecem ideais de como melhorar a qualidade de vida e evitar doenças. Com a realização da Copa do Mundo no Brasil, em 2014, o governo brasileiro juntamente com a FIFA está implantando tal projeto no país e conta com o apoio dos Ministérios da Saúde, Educação e Esporte. Esse projeto fornece um curso de capacitação para professores de Educação Física das 12 capitais que sediariam jogos do torneio. Nesta perspectiva, questionase: Os objetivos e métodos do projeto "Os 11 pela Saúde" atendem as reais necessidades da comunidade local?

Neste contexto, o presente estudo teve como objetivo analisar o projeto da FIFA "Os 11 pela Saúde" com intuito de identificar como são abordadas as áreas da Saúde, Educação, Esporte e Lazer.

\section{Metodologia}

Trata-se de uma pesquisa qualitativa, de cunho documental. Para Marconi e Lakatos (2011), uma pesquisa documental é caracterizada pelo fato de a coleta de dados estar restrita a documentos escritos ou não. Neste sentido, em um primeiro momento, foi realizada uma busca dos principais projetos advindos da FIFA, o que totalizou 13 projetos nas diferentes áreas do conhecimento. Neste caso, criaram-se alguns parâmetros para selecionar um único projeto, sendo considerados os seguintes critérios: foco no aspecto social, envolvimento com a Educação Física Escolar e a utilização do futebol na formação da sociedade e na promoção de valores pré-determinados pelos Ministérios e FIFA.

Portanto, o projeto "Os 11 pela Saúde" foi selecionado para análise e estudo, pois engloba os ideais da FIFA para três importantes áreas da sociedade: Saúde, Educação e Esporte, possibilitando um diálogo entre os Ministérios, a FIFA e a Educação Física. Além de ser o único, com atividades focadas especificamente para o contexto das aulas de Educação Física e a propagação de valores por meio do ambiente da Cultura Escolar.

Para melhor análise dos resultados, o projeto foi dividido em categorias a partir da análise de conteúdo (BARDIN, 2009) temática. Ou seja, foi realizado o desmembramento do texto, no caso, o projeto "Os 11 pela Saúde", que permitiu um olhar mais atento aos detalhes e particularidades do projeto e assim construídas as categorias de análises, sendo elas à saúde, à educação, ao esporte e ao lazer. Todos sob o viés do acesso a práticas de qualidade e ao atendimento ou não das reais necessidades e carências da educação e da comunidade brasileira em geral.

\section{Resultados}


O projeto "Os 11 pela Saúde" tem como grande idealizador o Phd em Medicina Esportiva, Prof. Colin Fuller, além de Prof. Jiri Dvorak e Dr. Astrid Junge, ambos médicos e colaborares do Centro de Pesquisa e Medicina da FIFA (F-MARC). Os idealizadores estudam e pesquisam no contexto voltado à medicina esportiva, sendo assim, nota-se ao analisar o projeto em questão uma forte tendência em transferir tais conhecimentos para o ambiente escolar.

Realizado especificamente no tempo e espaço das aulas da disciplina de Educação Física, o projeto é dividido em 11 seções que estão associados à Saúde, à Educação, ao Esporte e ao Lazer. Cada uma destas 11 seções é trabalhada em dois tempos de 45 min., simbolizando uma partida de futebol. O primeiro tempo denomina-se "Jogue futebol", ensina habilidades específicas do esporte. O segundo tempo é denominado de "Jogue limpo", informa sobre questões específicas e ensina comportamentos que podem gerar melhora na qualidade de vida.

Os diagramas, a seguir, elaborados pelos autores desta pesquisa demonstram um resumo das principais seções e eixos que o projeto se fundamenta e os valores que utiliza. $\mathrm{O}$ Diagrama 01 apresenta um resumo das seções e respectivos valores a serem transmitidos. A cor cinza claro remete à "mensagem de saúde", a flecha refere-se às "habilidades no futebol" e por fim, os "fatores de risco trabalhados" estão apresentados na cor branca.

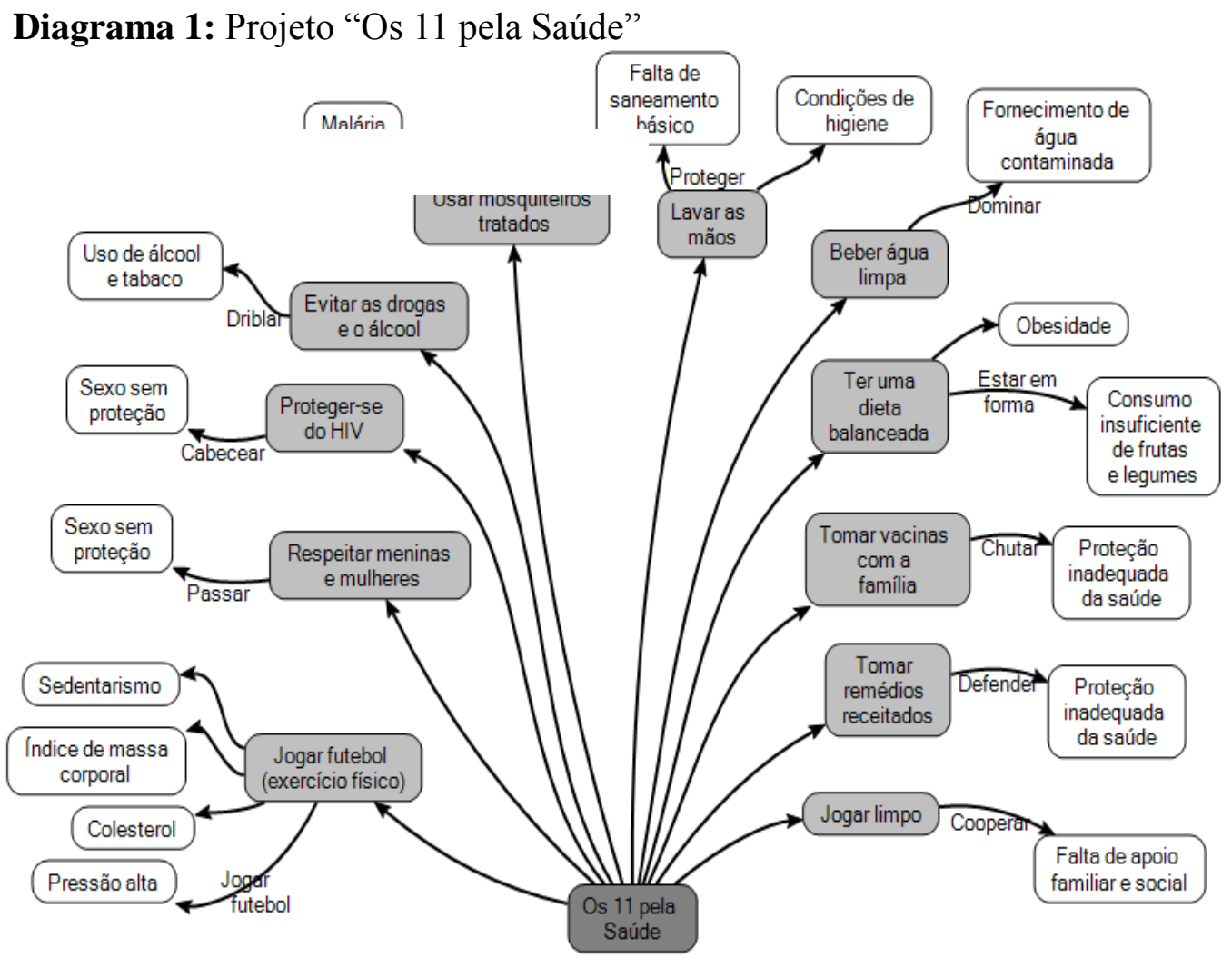

A partir da análise das seções do projeto, com intuito de melhorar a compreensão de como são abordadas a Saúde, a Educação, o Esporte e o Lazer, foi construído o Diagrama 2. $\mathrm{Na}$ cor branca, estão representadas as variáveis de maior frequência, no que diz respeito a cada categoria. 
Diagrama 2: As abordagens do Projeto "Os 11 pela Saúde”

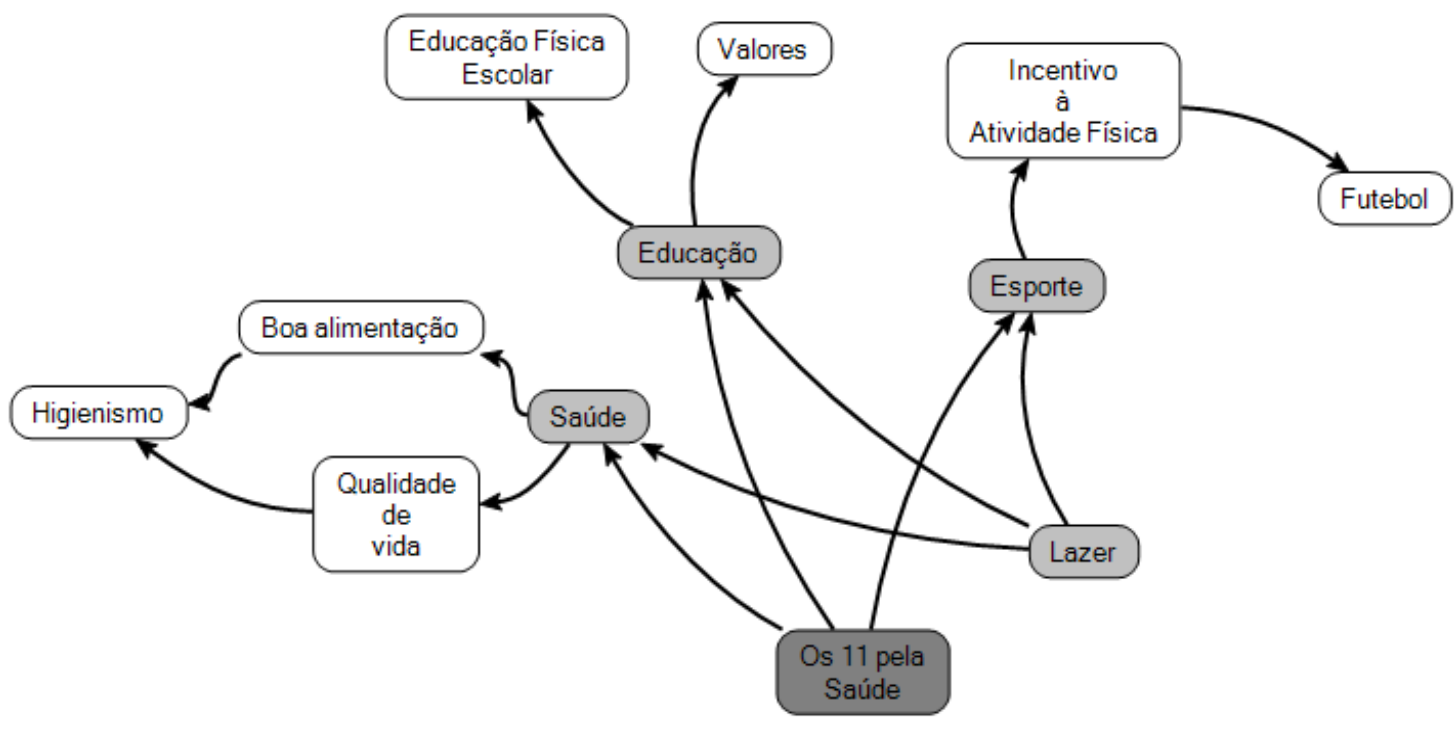

\section{Discussão}

Conforme o Ministério da Saúde (BRASIL, 2002), é no período escolar que se deve trabalhar questões relacionadas à Saúde, com o intuito de promover e desenvolver ações voltadas à qualidade de vida e prevenção de doenças. Para que isso ocorra, é preciso que todos os profissionais desenvolvam propostas curriculares com intenção de trabalhar na formação de bons hábitos.

Nesse sentido, a perspectiva do projeto "Os 11 pela saúde", implantado em escolas de cidade que receberam a Copa do Mundo visa promover o desenvolvimento de seções estabelecidas pela FIFA com a pretensão de por meio das habilidades específicas do futebol (como proteger, chutar, driblar, cabecear entre outros), estabelecer analogias com os hábitos saudáveis. "Bater bola", expressão relacionada ao ato de jogar futebol, é por exemplo, compreendido no projeto como algo saudável e que mantém a forma física o que é 
considerado muito importante para a proteção das doenças do dia a dia. Porém algumas colocações se mostram fora de contexto e não podem ser aplicadas a todas as cidades e principalmente, a todas as escolas, apresentando assim certas falhas de adaptabilidade e de reconhecimento que serão discutidas a seguir, visto que os países, mesmo que em desenvolvimento apresentam estágios diferentes de construção social e estrutural.

Em uma panorama geral, "Os 11 pela saúde" apresenta seu enfoque maior no eixo da saúde, voltado para a qualidade de vida e alimentação saudável. Percebe-se que o higienismo e seu conceito de saúde, em um viés considerado como ausência de doença, são fortemente marcados pela prática da atividade física e uma boa alimentação como principais responsáveis por uma vida produtiva e de qualidade.

Historicamente sabe-se que a Educação Física no Brasil teve fortíssimas influências médico-biológicas, onde a saúde, higiene e eugenia eram as bases para a sua prática (DARIDO, 2005). Desta forma, ao analisarmos o projeto "Os 11 pela saúde", nota-se que essa visão higienista se aproxima muito dos pressupostos do projeto, apontando que os exercícios físicos produzem muitos benefícios à saúde das crianças e adolescentes, entre eles a redução da ocorrência da obesidade, do diabetes, das doenças cardíacas e câncer, fatos que realmente já são comprovados pela ciência, no entanto, no projeto é limitado o espaço para uma discussão mais crítica e contextualizada em relação à prática que se oferta e sua relação com a saúde em sentido ampliado.

Desde a década de 70, a Educação Física passou a ter contato com teorias contrárias ao modelo tradicionais (BETTI, 1992). Para Darido (1999) em uma tentativa de romper o modelo hegemônico foram elaborados os primeiros pressupostos teóricos em um referencial crítico. Assim, na sociedade contemporânea a prática pedagógica da Educação Física deve ir além do contexto biológico/higiênico no que se tange o conceito de saúde, pautando-se também na possibilidade crítica e formativa do sujeito em seu sentido integral.

No eixo do Esporte, o projeto apresenta uma seção de incentivo à prática da atividade física, justificando a utilização do futebol, para atrair os jovens. Ao longo de suas 11 seções, o futebol é sempre citado como o veículo e agente de transformação social da comunidade. No entanto, algumas das justificativas da FIFA para o seu uso são percebidas por esse estudo como desconexas com a realidade vivida e de certa maneira ausente dos riscos, danos e também da ciência sobre as precárias condições para o acesso ao esporte de qualidade que a maioria dos brasileiros enfrenta.

De fato, o futebol é praticado e acompanhado por milhares de pessoas em todo o mundo, e no Brasil possui mais de 100 milhões de pessoas que o acompanham de alguma forma, mas se questiona como trabalhar com a ideia da prática predominantemente esportiva do futebol nas aulas de Educação Física curriculares, e aqui damos ênfase ao predominantemente esportiva, visto que o projeto não apresenta em seu escopo propostas de discussões ampliadas sobre a prática.

Sabe-se que o esporte tende a possuir potencial em qualquer comunidade do mundo, porém o projeto se refere a uma prática de qualidade, como algo acessível a todos e em muitos casos, na realidade brasileira, esse acesso não existe. Muitos não têm condições básicas de vida e após as aulas têm que retornar aos seus trabalhos e contextos sociais fragilizados.

Outro fator é que não somente a prática esportiva pode melhorar a qualidade de vida, a prática pela prática, muitas vezes sem sentido algum ou que não condiz com a realidade do sujeito, acabam sendo vazias não propiciando a criação de significados para o jovem que o 
pratica.

Para Libaneo (1994, p. 222), o processo de ensino-aprendizagem se efetiva a partir de um "processo de racionalização, organização e coordenação da ação docente, articulando a atividade escolar e a problemática do contexto social". Fica claro neste sentido, que deve haver uma preocupação em integrar a ação à problemática do contexto social dos sujeitos.

Desta forma, o esporte não deve ser visto como um fenômeno isolado. Por mais que sua prática esteja no gosto popular, o futebol carrega uma série de preconceitos e paradigmas que a FIFA em nenhum momento menciona em seu projeto e em suas recomendações de aplicação do mesmo. Muitos alunos não têm aptidão física, nem aguçado controle motor para se destacar na prática esportiva e até mesmo na prática escolar.

Destaca-se que o futebol pode sim, como prática esportiva, ser um agente potencializador de determinados valores considerados importantes. Porém, é necessário deixar claro que não apenas com o futebol haverá melhor qualidade de vida da comunidade onde o jovem está inserido, e que apenas sua prática, desvinculada de ações reflexivas e da compreensão dos diferentes contextos sociais, dificilmente gerará mudanças.

Sabe-se que a FIFA é um órgão relacionado ao futebol, o que justifica a escolha do esporte, porém deve-se considerar que, ao ocupar o tempo da Educação Física curricular, que busca nos dias atuais um enfoque mais crítico e reflexivo frente às questões relacionadas a Cultura Corporal do Movimento, o projeto passa a necessidade de repensar suas ações e discurso, buscando se integrar à dinâmica da comunidade, da escola e da Educação Física e não o inverso. Pensar nesses conteúdos inseridos nas aulas de Educação Física, remete a "considerar que as expressões corporais são manifestações humanas, culturais, influenciadas pelo contexto em que os sujeitos estão inseridos e que a disciplina lida com a dinâmica simbólica desses elementos da cultura corporal do movimento" (SILVA, 2013, p. 221).

No que se refere ao eixo lazer, nota-se que este fenômeno se faz presente em cada categoria de análise do presente estudo. Com forte embasamento no imaginário e na paixão pelo futebol, o potencial simbólico é aliado a diversas áreas da sociedade. Dentre essas áreas, está o lazer, sua multiplicidade de setores e a necessidade de entendê-lo mais especificamente inserido em diversos contextos sociais, culturais e econômicos.

De acordo com Mascarenhas (2004, p. 103), o lazer pode ser considerado "um fenômeno tipicamente moderno, resultante das tensões entre capital e trabalho, que se materializa como um tempo e espaço de vivências lúdicas, lugar de organização da cultura, perpassado por relações de hegemonia". É dessa forma, que essas vivências aprendidas na escola podem ser levadas ao cotidiano das crianças e adolescentes, mas tudo vai depender de como esses princípios apresentados no projeto estão sendo aplicados para esses sujeitos.

No tocante à educação, uma das justificativas do projeto é a conscientização no ambiente escolar para a aquisição de hábitos saudáveis. A partir desse pressuposto, o projeto explora o tempo e o espaço das aulas de Educação Física, exercendo papel de protagonizar desse encontro entre os valores e objetivos da FIFA e dos Ministérios da Saúde, Educação e Esporte. Todavia, entende-se que o tempo do projeto é reduzido, além de se limitar apenas a uma prática corporal.

Por fim, verificou-se que o projeto apresenta aspectos positivos, principalmente na tentativa de tornar atrativo para parte dos alunos, assuntos que são considerados delicados e difíceis de trabalhar com as crianças e jovens. Sob o aspecto negativo repousa mais uma vez um descaso com as condições de acesso aos valores ensinados.

Para que os objetivos propostos sejam de fato atingidos, é necessária maior atenção

Pensar a Prática, Goiânia, v. 18, n. 4, out./dez. 2015 
com as dificuldades de acesso em que o povo brasileiro se encontra atualmente, estando muitas cidades sem médicos e sem condições mínimas de saneamento básico. $\mathrm{O}$ projeto não tem "força" para minimizar esses problemas, muito menos solucioná-los. Neste sentido, seria mais interessante que o mesmo gerasse a mobilização dos alunos para o reconhecimento ao direito de acesso a estas condições ao invés de propriamente ensiná-los a terem condutas que não condizem com a realidade das crianças e adolescentes. Nessas realidades somente a instrução de hábitos saudáveis e de higiene acabam sendo ineficazes e não geram melhorias consideráveis na qualidade de vida da população.

Entender que o ensino se faz em diversas culturas escolares e que cada cultura apresenta suas particularidades e carências específicas torna a execução e continuidade do projeto uma incógnita após os dias de competição.

No Brasil, ainda não existem pesquisas realizadas para verificar a efetividade e os resultados do projeto, pois o mesmo encontra-se em fase de aplicação nas escolas. Já no contexto africano após a Copa do Mundo de 2010, de acordo com o Centro de Pesquisa e Avaliação Médica da FIFA (F-MARC), o projeto resultou no aumento significativo do conhecimento no que se refere aos hábitos saudáveis das crianças (FIFA, 2014). No entanto, acredita-se que tais resultados são questionáveis, primeiramente pelo fato da pesquisa ser realizada pela própria instituição que o propõe, em seguida pela metodologia empregada para avaliação dos resultados, que é composta de uma breve pesquisa entre os alunos atendidos ao final do projeto e do evento. Não existe um acompanhamento em longo prazo, a respeito do comportamento destas crianças após a Copa do Mundo.

Cabe destacar que mesmo sendo realizado na escola, em parceria com professores, o projeto não apresenta intenções de melhorar as estruturas das escolas, principalmente no que se refere ao espaço físico onde são realizadas as aulas de Educação Física, o que aumenta a complexidade de desenvolver as ações propostas pela própria FIFA.

Tokuyochi (2008) entrevistou 2.700 professores da rede estadual de São Paulo e constatou que a maior dificuldade dos profissionais é a falta de infraestrutura física adequada para o desenvolvimento das aulas.

De acordo com Silva (2013, p. 229), tratando dos Megaeventos Esportivos, a realização de tais eventos ao contrário do que se espera pode proporcionar perdas para a Educação Física Escolar, pois, há um reforço no que já acontece em grande parte do cotidiano dessas aulas, o foco no esporte de alto rendimento.

A autora frisa que "a escola não tem infraestrutura exigida para esse modelo de esporte por exemplo. Não tem materiais, espaços, profissionais (médicos, fisioterapeutas etc.) nem alunos que atendam aos pressupostos do alto rendimento no que tange à aptidão física".

Rechia et al. (2013) apontam que entre os espaços que permitem a vivência da dimensão lúdica na sociedade moderna, o espaço da escola é um ambiente privilegiado, assim, o espaço físico das aulas de Educação Física é essencial para o seu desenvolvimento.

Ao analisar o projeto "Os 11 pela Saúde", elaborado por profissionais da área médica, percebe-se o quanto um professor da área da Educação Física poderia contribuir para a formulação de um projeto que contemplasse também a formação de alunos mais críticos e reflexivos, aptos a conquistar a autonomia, por meio do "conhecimento, reflexão e transformação da cultura corporal” (SOUZA JÚNIOR; DARIDO, 2010, p. 2).

Entende-se que se o projeto "Os 11 pela Saúde" tem como um dos objetivos difundir valores relacionados à saúde, e mesmo tendo como ferramenta específica o futebol, seria interessante diversificar as práticas corporais, para ampliar a possibilidade de inclusão entre 
os sujeitos participantes (SOUZA JÚNIOR; DARIDO, 2010).

\title{
Considerações Finais
}

Após análise do projeto e suas seções, é possível inferir com base na realidade vivenciada no Brasil que o projeto "Os 11 pela Saúde" apresenta certo distanciamento com a realidade das crianças e jovens participantes do projeto. Além disso, percebeu a generalização de alguns dos problemas de países em desenvolvimento, não se aprofundando nas diferentes realidades de cada país. Fato que torna algumas seções do projeto inaplicáveis em diversas regiões brasileiras.

De todo modo, deve-se reconhecer que o projeto "Os 11 pela Saúde" tem uma iniciativa social interessante, mas necessita estabelecer um diálogo mais próximo com a escola, com os professores de Educação Física e, principalmente, com a comunidade, para que valores como saúde, educação, esporte e lazer sejam concretizados a partir das fragilidades e interesses da população.

Destaca-se também a importância do melhor entendimento da formulação de políticas públicas e projetos a serem aplicados no país, tendo em vista as reais necessidades da população brasileira, ressaltando que para que isso ocorra, a construção de tais projetos não podem ser realizadas de forma autocráticas. Por fim, sugerem-se novas pesquisas para acompanhar o andamento e os resultados da aplicação do projeto "Os 11 pela Saúde" nas diferentes escolas brasileiras.

\section{FIFA PROJECT "THE 11 FOR HEALTH": A QUALITATIVE ANALYSIS}

\begin{abstract}
The project "The 11 for Health" is a FIFA initiative, developed in physical education classes in some of the host cities for the World Cup. However wonders: The goals and methods of the "The 11 for Health" meet the real needs of the local community? Thus, this article presents a documentary study that aims analyzing the FIFA project "The 11 for Health" to identify how it addresses to the areas of Health, Education, Sports and Leisure. We used the method of thematic content analysis. It was realized that the project has a hygienist perspective and that some of their perspectives aren't consistent with the Brazilian reality. It was observed that it is necessary a closer dialogue between the organizers of the project, physical education teachers, school and the community in general so that values such as Health, Education, Sports and Leisure could be accomplished from the weaknesses and interests of the population.
\end{abstract}

Keywords: Leisure Activities. Physical education. Sport. World Cup.

\section{PROYECTO FIFA “LOS 11 POR LA SALUD”: UN ANÁLISIS CUALITATIVO}

\section{Resumen}

El proyecto "Los 11 por la Salud" se trata de una iniciativa de la FIFA, desarrollado en las clases de Educación Física en algunas de las ciudades anfitrionas de la Copa Mundial. Sin embargo se pregunta: ¿Los objetivos y los métodos del proyecto"Los 11 por la Salud" satisfacen las necesidades reales de la comunidad local? De esta forma, este artículo se presenta un estudio documental que tuvo como objetivo analizar el proyecto de la FIFA "Los 11 por la Salud" para identificar cómo son abordadas las 
áreas de Salud, Educación, Deportes y Ocio. Se utilizó el análisis de contenido temático. Se consideró que el proyecto tiene una perspectiva higienista y algunos de sus puntos de vista no son coherentes con la realidad brasileña. Se observó que es necesario un diálogo más estrecho entre los organizadores del proyecto, los profesores de Educación Física, la escuela y la comunidad en general para que los valores tales como Salud, Educación, Deportes y Tiempo Libre sean concretizados a partir de las debilidades e intereses de la población.

Palabras clave: Copa Mundial. Educación Física. Ocio. Deporte.

\section{Referências}

BARDIN, L. Análise de conteúdo. Lisboa: Edições 70, 2009.

BETTI, M. Ensino de primeiro e segundo graus: Educação Física para quê? Revista do Colégio Brasileiro de Ciências do Esporte, v.13, n.2, 1992. p. 282-287.

BRASIL. Ministério da Saúde. Secretaria de Políticas de Saúde. Projeto promoção da saúde. A promoção da saúde no contexto escolar. Revista de Saúde Pública, São Paulo, v. 36, n. 4, 2002. p.533-535.

DARIDO, S.C. Ação pedagógica do professor de Educação Física. (Tese de Doutorado) Instituto de Psicologia, Universidade de São Paulo, 1999.

DARIDO, S. C.; RANGEL, I. C. A. Educação Física na escola: implicações para prática pedagógica. Editora Guanabara Koogan, 2005.

FIFA. Programa "11 pela Saúde" da FIFA é lançado no Brasil. Disponível em:< http://pt.fifa.com/worldcup/news/newsid=2150414/>. Acesso em: 29 abr. 2014.

FIFA. Football for health (futebol pela saúde) - sessão 5: usar mosquiteiros tratados. Disponível em: <http://pt.fifa.com/aboutfifa/footballdevelopment/medical/footballforhealth/session5.html>. Acesso em: 30 nov. 2013a.

FIFA. Football for health (Futebol Pela Saúde) - Sessão 10: Tomar remédios receitados. Disponível em:

http://pt.fifa.com/aboutfifa/footballdevelopment/medical/footballforhealth/session10.html>. Acesso em: 30 nov. 2013b.

FIFA. Football for health (Futebol Pela Saúde) - Sessão 1: Jogar futebol. Disponível em: $<$

http://pt.fifa.com/aboutfifa/footballdevelopment/medical/footballforhealth/session1.html . Acesso em: 30 nov. $2013 \mathrm{c}$.

GUIMARÃES, A. A.; PELLINI, F. C.; ARAÚJO, J. S. R.; MAZZINI, J. M. Educação Física Escolar: atitudes e valores. Motriz, Rio Claro, v. 7, n. 1, 2001. p. 17-22. 
LIBÂNEO, J. C. Didática. São Paulo. Editora Cortez. 1994.

MARCONI. M. A.; LAKATOS. E. M. Técnicas de pesquisa. São Paulo: Atlas, 2011.

MATIAS, M. Organização de Eventos: procedimentos e técnicas. 4. ed. rev. e ampl. Barueri: Manole, 2007.

RECHIA, S. et al. Os Espaços retratados no Colégio Estadual do Paraná: Diferentes Olhares, Uma Mesma Realidade. Licere, Belo Horizonte, v. 16, n. 4, 2013.

RUBIO, K. Megaeventos esportivos, legados e responsabilidade social. São Paulo: Casa do psicólogo, 2007.

SÁNCHES, F.; BIENENSTEIN, G.; MASCARENHAS, G. Pós-escrito: 2014 e 2016, quem define o jogo? In: MASCARENHAS, G.; BIENENSTEIN, G.; SÁNCHES, F. O jogo continua: megaeventos esportivos e cidades. Rio de Janeiro: EdUERJ, 2011.

SILVA, C. L. Legados de Megaeventos Esportivos: perdas e ganhos para educação física escolar. In: MARCELLINO, N. C. Legados de Megaeventos Esportivos. Campinas: Papirus, 2013.

SOARES, C. L. Educação Física - raízes européias e Brasil. Campinas: Autores Associados, 2012.

SOUZA JÚNIOR, O. M.; DARIDO, S. C. Refletindo sobre a tematização do futebol na Educação Física Escolar. Motriz, Rio Claro, v. 16, n. 4, 2010. p. 920-930.

TOKUYOCHI, J. H. et al. Retrato dos professores de Educação Física das escolas estaduais do estado de São Paulo. Motriz, Rio Claro, v.14 n.4, 2008. p.418- 428.

Recebido em: 17/03/2015

Revisado em: 17/07/2015

Aprovado em: 20/09/2015

Endereço para correspondência:

milapcosta@ hotmail.com

Emília Amélia Pinto Costa Silva

Universidade Federal do Paraná, Setor de Ciências Biológicas, Departamento de Educação Física.

Rua Coração de Maria, 92

Jardim Botânico

80210-132 - Curitiba, PR - Brasil 